\title{
PRECLINICAL DETECTION OF CHEMOTHERAPY INDUCED LEFT VENTRICULAR DYSFUNCTION IN PATIENTS WITH CANCER COLON BY TRANSTHORACIC ECHOCARDIOGRAPHY
}

\author{
By \\ Mohammed Abd El-Ghafar Salim, Wael Mohammed Attia and Ayman \\ Sadek El-Saied \\ Department of Cardiology, Faculty of Medicine, Al-Azhar University \\ E-mail: dr.Salim91@yahoo.com , Phone: 01026525033
}

\begin{abstract}
Background: Cancer colon is one of the most common malignancies which treated by chemotherapy. Cardiotoxicity is one of the most important adverse reactions of chemotherapy, leading to an important increase in morbidity and mortality; it can appear early or late in the course of the disease.

Objective: To detect early changes in LV mechanics and to determine if 2D-STE could predict preclinical cardiotoxicity from chemotherapeutic treatment in patients with cancer colon.

Patients and methods: The study included 30 patients with cancer colon, age ranged from 36 - 55 years and 20 healthy controls with age ranged from $32-55$ years. Both groups were matched in age and sex. Clinical evaluation (included full history taking general and local examination) and transthoracic echocardiographic examination (TTE), 2-D speckle tracking echo (2D-STE) were performed to all subjects.

Results: 2D-STE showed that apical 2, 3, and 4 chambers longitudinal strain percent as well as Global longitudinal strain (GLS) of the studied patients and controls showed statistically significant difference between controls, pre- and post-chemotherapy. In comparison between control and pre-treatment showed statistically non-significant difference, while comparison between control and post-treatment as well as preand post-treatment showed statistically highly significant difference.

Conclusion: A substantial impairment of LV systolic function was detecting in cancer colon patients receiving chemotherapy with apparently preserved LV systolic function as evidenced by reduction in global longitudinal strain using two-dimensional speckle tracking echocardiography.
\end{abstract}

Keywords: Chemotherapy, left ventricular dysfunction, cancer colon patient, transthoracic echocardiology.

\section{INTRODUCTION}

Colorectal cancer (CRC) is one of the most common malignancies, accounting for approximately 1.36 million new cases worldwide every year. It is the third most common cancer behind lung and prostate cancer in men and the second most common after breast cancer in women (Ferlay et al., 2015). CRC is a disease of aging and largely affects the elderly population (Jung et al., 2014).

Cancer treatment has significantly improved and it has been proved to increase significantly rate of cure in cancer colon, as well as to reduce recurrences. However, the applicability of these drugs is limited by the risk of cardiotoxicity (Brana and Tabernero, 2010). 
Cardiotoxicity is one of the most important adverse reactions of chemotherapy, leading to an important increase of morbidity and mortality (Cardinale et al., 2010). It can appear early or late in the course of the disease, and may vary from subclinical myocardial dysfunction to irreversible heart failure or even death (Mercuro et al., 2007).

Data on the mechanism of the appearance of cardiac dysfunction during chemotherapy and the susceptibility of patients to develop cardiotoxicity are scarce (Khakoo et al., 2011).

Overtime, recommendations of diagnosis of cardiac dysfunction induced by chemotherapy used functional and structural parameters of conventional echocardiography, such as left ventricular (LV) ejection fraction (EF), fractional shortening (FS), as well as diameters and volumes (Sawaya et al., 2011).

However, these conventional measurements allow only the late diagnosis of cardiac dysfunction, which might be already irreversible. Therefore, there is a major need for other accurate and reproducible parameters, able to detect early, subclinical, LV dysfunction and, thus, able to identify patients at risk for rapid progression toward irreversible cardiac failure, who can benefit from early therapeutic measures (Tsai et al., 2011 and Florescu et al., 2013).

The aim of the study was to detect the early changes in LV mechanics, and to determine if 2D-STE could predict preclinical cardiotoxicity from chemotherapeutic treatment after the first and second cycle of chemotherapy in patients with cancer colon.

\section{PATIENTS AND METHODS}

This was a case-control study, where 30 patients diagnosed with cancer colon collected from the Oncology Department, Al-Azhar University Hospitals, and 20 normal controls. The study was performed at Cardiology Department, Al-Azhar Faculty of Medicine during the period from January 2019 to January 2020. A written informed consent was taken from each patient, and the study was approved by our ethical committee.

\section{Inclusion Criteria:}

Patients with cancer colon who were receiving chemotherapy with $\mathrm{LV}$ ejection fraction $(\mathrm{EF}) \geq 50 \%$.

\section{Exclusion Criteria:}

Patients with documented IHD, patients with history of cardiac intervention (PCI or CABG), patients with moderate or severe valvular disease, patients with conduction abnormalities, pacemaker, ongoing arrhythmia and bundle branch block, patients with congenital heart disease, patients with EF $\leq 50 \%$ or cardiomyopathy, atrial fibrillation, end stage renal disease, poor echocardiographic window, or patient refusal.

\section{All patients were subjected to:}

1. Clinical evaluation which included full history taking, general and local examination.

2. Echocardiographic examination before and after ending chemotherapy:
A. Standard
trans-thoracic echocardiographic study (TTE): TTE was performed using S4-2 transducer 4-2 $\mathrm{MHz}$ with a 
commercially available ultrasound system (Philips, IE 33, Andover, MA, USA) according to the standardized protocol, LV internal dimensions, LV end-diastolic dimensions, and end-systolic dimensions, LV EF by Biplane Simpson's method.

B. 2D strain imaging by speckle tracking (2D-STE): 2D echocardiography images were obtained from apical four, apical three and apical two chamber views. All images were stored in cine-loop format from three consecutive beats. The frame rate for images was between 50 and 90 frames/s, while analysis was performed off-line using commercially available software (Philips QLAB Advanced Quantification Software version 8.1) (Gjesdal et al., 2007).

\section{Statistical analysis:}

The collected data were analyzed by computer using Statistical Package for the Social Science version 22 (SPSS), Data were represented in tables, Continuous Quantitative variables; e.g. age were expressed as the mean $\pm \mathrm{SD}$ and range, and categorical qualitative variables were expressed as absolute frequencies (number) and relative frequencies (percentage).

Suitable statistical tests of significance were used after checked for normality. ANOVA followed by post-hoc test was used for test of significance such as Chi square and student's-t-test. The results were considered statistically significant when the significant probability was less than 0.05 .

\section{RESULTS}

The study included 30 patients with age ranged from $36-55$ years and mean \pm SD of $43.03 \pm 6.31$ years and 20 controls with age ranged from $32-55$ years and mean of $45.05 \pm 5.56$ years. Both groups were matched in age and sex as they showed statistically insignificant difference (Table 1).

Table (1): Comparison between patients and control according age and sex

\begin{tabular}{|c|c|c|c|}
\hline Demographic data & $\begin{array}{c}\text { Control } \\
(n=20)\end{array}$ & $\begin{array}{c}\text { Patients } \\
(n=30)\end{array}$ & p-value \\
\hline \multicolumn{4}{|l|}{ Age (years) } \\
\hline Mean \pm SD & $45.05 \pm 5.56$ & $43.03 \pm 6.31$ & $>0.05$ \\
\hline \multicolumn{4}{|l|}{ Sex } \\
\hline Male: N (\%) & $13(65.0 \%)$ & $20(66.7 \%)$ & \multirow{2}{*}{$>0.05$} \\
\hline - $\quad$ Female: N (\%) & $7(35.0 \%)$ & $10(33.3 \%)$ & \\
\hline
\end{tabular}

The finding of left ventricular end diastolic diameter (LVEDD), left ventricular end systolic diameter (LVESD), left ventricular end diastolic volume (LVEDV), left ventricular end systolic volume (LVESV) and left ventricular ejection fraction percent (LVEF\%) of the studied patients and 
controls showed statistically insignificant chemotherapy (Table 2). values between controls, pre- and post-

Table (2): Comparison of echocardiographic parameters between patients and control groups

\begin{tabular}{|c|c|c|c|c|}
\hline \multirow[b]{2}{*}{ LVEDD (cm) } & \multicolumn{2}{|c|}{ Range } & \multirow{2}{*}{$\begin{array}{c}\text { Subjects } \\
\text { Mean } \pm \text { SD }\end{array}$} & \multirow{2}{*}{ p-value } \\
\hline & Min & Max & & \\
\hline Control & 4 & 5.6 & $4.86 \pm 0.41$ & \multirow{3}{*}{$>0.05$} \\
\hline Pre-treatment & 4 & 5.6 & $4.97 \pm 0.36$ & \\
\hline Post-treatment & 4 & 5.6 & $5.03 \pm 0.35$ & \\
\hline \multicolumn{5}{|l|}{ LVESD (cm) } \\
\hline Control & 2.5 & 3.6 & $3.16 \pm 0.36$ & \multirow{3}{*}{$>0.05$} \\
\hline Pre-treatment & 2.65 & 3.6 & $3.21 \pm 0.24$ & \\
\hline Post-treatment & 2.6 & 3.6 & $3.30 \pm 0.25$ & \\
\hline \multicolumn{5}{|l|}{ LVEDV (ml) } \\
\hline Control & 70 & 153.7 & $111.64 \pm 21.7$ & \multirow{3}{*}{$>0.05$} \\
\hline Pre-treatment & 70 & 141.3 & $117.33 \pm 18.8$ & \\
\hline Post-treatment & 70 & 141.3 & $120.76 \pm 18.2$ & \\
\hline \multicolumn{5}{|l|}{ LVESV (ml) } \\
\hline Control & 21.2 & 54.4 & $40.39 \pm 10.9$ & \multirow{3}{*}{$>0.05$} \\
\hline Pre-treatment & 25.8 & 54.4 & $41.78 \pm 7.35$ & \\
\hline Post-treatment & 24.6 & 54.43 & $44.68 \pm 7.93$ & \\
\hline \multicolumn{5}{|l|}{ LVEF (\%) } \\
\hline Control & 53.2 & 79.47 & $64.57 \pm 7.12$ & \multirow{3}{*}{$>0.05$} \\
\hline Pre-treatment & 57.8 & 72.95 & $64.20 \pm 4.34$ & \\
\hline Post-treatment & 57.8 & 70.72 & $63.02 \pm 3.24$ & \\
\hline
\end{tabular}

The findings of 2D-STE showed that apical 2, 3, and 4 chambers longitudinal strain percent as well as GLS of the studied patients and controls showed statistically highly significant difference between controls, pre- and postchemotherapy $(\mathrm{P}<0.001)$. Comparison between control and pre-treatment showed statistically non-significant difference, while comparison between control and post-treatment as well as pre- and posttreatment showed statistically significant difference (Table 3). 
PRECLINICAL DETECTION OF CHEMOTHERAPY INDUCED LEFT...

Table (3): Comparison of 2D-STE between patients and control group

\begin{tabular}{|c|c|c|c|c|c|c|}
\hline \multirow{2}{*}{$\begin{array}{l}\text { Mitral E } \\
\text { (cm/sec.) }\end{array}$} & \multicolumn{2}{|c|}{ Range } & Subjects & \multirow{2}{*}{\multicolumn{3}{|c|}{$\frac{\text { Test of significance }}{\text { p-values }}$}} \\
\hline & Min & $\operatorname{Max}$ & Mean \pm SD & & & \\
\hline Control & 59 & 111 & $89.12 \pm 18.16$ & \multirow{3}{*}{$>0.05$} & P1 & 0.451 \\
\hline Pre-treatment & 65 & 118 & $92.60 \pm 14.93$ & & $\mathrm{P} 2$ & 0.231 \\
\hline Post-treatment & 51 & 118 & $94.67 \pm 15.22$ & & $\mathrm{P} 3$ & 0.616 \\
\hline \multicolumn{7}{|c|}{ Mitral A (cm/sec.) } \\
\hline Control & 56 & 95 & $77.27 \pm 10.46$ & \multirow{3}{*}{$>0.05$} & P1 & 0.375 \\
\hline Pre-treatment & 50 & 95 & $74.53 \pm 10.75$ & & $\mathrm{P} 2$ & 0.393 \\
\hline Post-treatment & 50 & 95 & $74.63 \pm 10.62$ & & P3 & 0.971 \\
\hline \multicolumn{7}{|c|}{ Mitral E/A ratio } \\
\hline Control & 0.74 & 1.73 & $1.17 \pm 0.28$ & \multirow{3}{*}{$>0.05$} & $\mathrm{P} 1$ & 0.245 \\
\hline Pre-treatment & 0.85 & 2 & $1.27 \pm 0.29$ & & $\mathrm{P} 2$ & 0.147 \\
\hline Post-treatment & 0.81 & 2 & $1.29 \pm 0.29$ & & P3 & 0.745 \\
\hline \multicolumn{7}{|l|}{ Em $(\mathrm{cm} / \mathrm{sec})}$. \\
\hline Control & 5 & 13.6 & $8.83 \pm 2.66$ & \multirow{3}{*}{$>0.05$} & $\mathrm{P} 1$ & 0.190 \\
\hline Pre-treatment & 6.4 & 13 & $9.63 \pm 1.89$ & & $\mathrm{P} 2$ & 0.190 \\
\hline Post-treatment & 6.4 & 13 & $9.63 \pm 1.89$ & & P3 & 1.000 \\
\hline \multicolumn{7}{|c|}{ Mitral E/Em ratio } \\
\hline Control & 6.2 & 17.45 & $10.71 \pm 3.08$ & \multirow{3}{*}{$>0.05$} & $\mathrm{P} 1$ & 0.229 \\
\hline Pre-treatment & 6.54 & 14.75 & $9.86 \pm 1.96$ & & $\mathrm{P} 2$ & 0.420 \\
\hline Post-treatment & 6.67 & 15.31 & $10.14 \pm 2.41$ & & P3 & 0.655 \\
\hline \multicolumn{7}{|l|}{ AP2 LS } \\
\hline Control & -26 & -20 & $-23.40 \pm 1.73$ & \multirow{3}{*}{0.001} & P1 & 0.235 \\
\hline Pre-treatment & -27 & -21 & $-24.53 \pm 1.57$ & & $\mathrm{P} 2$ & 0.006 \\
\hline Post-treatment & -27 & -11 & $-20.70 \pm 4.91$ & & P3 & 0.001 \\
\hline \multicolumn{7}{|l|}{ AP3 LS } \\
\hline Control & -26 & -20 & $-23.20 \pm 1.36$ & \multirow{3}{*}{0.001} & P1 & 0.237 \\
\hline Pre-treatment & -26 & -21 & $-24.23 \pm 1.25$ & & $\mathrm{P} 2$ & 0.001 \\
\hline Post-treatment & -25 & -11 & $-20.33 \pm 4.60$ & & P3 & 0.001 \\
\hline \multicolumn{7}{|l|}{ AP4 LS } \\
\hline Control & -26 & -18 & $-22.55 \pm 2.76$ & \multirow{3}{*}{0.001} & $\mathrm{P} 1$ & 0.537 \\
\hline Pre-treatment & -27 & -19 & $-23.13 \pm 2.53$ & & $\mathrm{P} 2$ & 0.001 \\
\hline Post-treatment & -27 & -12 & $-19.40 \pm 4.09$ & & $\mathrm{P} 3$ & 0.001 \\
\hline \multicolumn{7}{|l|}{ GLS } \\
\hline Control & -26 & -14 & $-22.83 \pm 2.58$ & \multirow{3}{*}{0.001} & P1 & 0.401 \\
\hline Pre-treatment & -26 & -14 & $-23.62 \pm 2.14$ & & $\mathrm{P} 2$ & 0.001 \\
\hline Post-treatment & -24 & -12 & $-18.08 \pm 4.35$ & & P3 & 0.001 \\
\hline
\end{tabular}

P1: compare control and pre-treatment, P2: compare control and post-treatment, P3: compare pretreatment and post-treatment.

\section{DISCUSSION}

The present study included $10 \%$ of patients with diabetes mellitus (DM) and $13.3 \%$ had hypertension, while none of the control subjects had DM or hypertension. Statistically there was an insignificant difference between both groups as regard DM and hypertension.

In comparison with the existing literature, Balloni et al. (2000) reported classic two-dimensional echocardiographic indices of LV function with normal baseline ECG and vital 
treated with 5-FU. No changes in ECG, $\mathrm{BP}$, or heart rate were noted.

Early detection of cardiotoxicity has predominantly relied upon serial cardiac imaging to identify a reduction in left ventricular function without signs or symptoms of heart failure (stage B HF) (Yancy et al., 2013).

The use of LVEF has important limitations. The measurements of LVEF are subject to technique-related variability, which can be higher than the thresholds used to define cardiotoxicity. The reduction in LVEF is often alate phenomenon, with failure to recover systolic function in up to $58 \%$ of patients despite intervention. STE is an echocardiography technique that allows a precise evaluation of myocardial function. This method is accurate, reproducible, and angle independent, and it enables a complete assessment of regional and global function in three directions (Telli et al., 2007).

Płońska-Gościniak et al. (2017) studied adverse effects of 5-FU on the cardiovascular system in $16 \mathrm{CRC}$ patients (age 39-74) with initially normal BP, ECG, and echocardiogram. No other deviations in BP and heart rate were detected.

Echocardiography findings at baseline were within currently recommended reference ranges except for a minor increase in septal wall thickness and a decrease in S'IVS (Lang et al., 2015).

The finding of left ventricular end diastolic diameter, left ventricular end systolic diameter (LVESD), left ventricular end diastolic volume (LVEDV), left ventricular end systolic volume (LVESV) and left ventricular ejection fraction percentage (LVEF\%) of the studied patients and controls showed statistically insignificant values between controls, pre- and post-chemotherapy. This was in agreement with PłońskaGościniak et al. (2017) who found, throughout 12 months of follow-up, LVEF remained normal. LVEDD and LVESD during chemotherapy were slightly larger and returned to baseline values after 12 months. Balloni et al. (2000) reported that echocardiography findings (LVEDD, LV mass) remained unaffected both after six cycles of 5-FU and six months after completion of chemotherapy.

The finding mitral $\mathrm{E}$, Mitral $\mathrm{A}$ and Mitral E/A ratios as well as Em and E/Em ratios of the studied patients and controls showed statistically insignificant values between controls, pre- and postchemotherapy.

These data opposed that of PlońskaGościniak et al. (2017) who found a significant worsening in $\mathrm{LV}$ functional parameters by tissue Doppler. They added that after a year from chemotherapy initiation E'sept decreased. Furthermore, concurrently both S'IVS and S'lat have dropped. No other meaningful changes were identified by TTE after 12 months which coincides with our study.

Normal ranges for GLS defined in the meta-analysis published in 2013 by Yingchoncharoen et al. (2013) support the use of a normal cut-off exceeding $-19 \%$, further confirmed by the cardiotoxicity study review who found GLS values $<19 \%$ in all patients who later developed heart failure (Thavendiranathan et al., 2014). However, because of baseline variability in strain values between 
different patients, the strongest predictor of LV dysfunction may be the change in GLS when compared with baseline values (Venneri et al., 2018). A change $>15 \%$ from baseline is considered to be of clinical significance (Plana et al., 2014). Studies suggest that the evaluation of LV twist with speckle tracking has incremental value for detecting early myocardial damage, but this requires further study (Mornos and Petrescu, 2013).

In the present study, 2D-STE showed that apical 2, 3, and 4 chambers longitudinal strain percent as well as Global longitudinal strain (GLS) of the studied patients and controls showed statistically significant difference between controls, pre- and post-chemotherapy. Comparison between control and pretreatment showed statistically nonsignificant difference, while comparison between control and post-treatment as well as pre- and post-treatment showed statistically significant difference.

Myocardial deformation imaging is a helpful tool for the sensitive detection of LV function but has some limitations. The global strain is calculated as the average of the analyzed segmental strain values (Tsai et al., 2011).

If the image quality is low and many segments must be discarded, the global strain might be misjudged (Gjesdal et al., 2008).

In the present study, longitudinal strain values were obtained in sensitivity of $83 \%$ of segments, demonstrating that 2D-STE was feasible in most patients. Our patients were examined in a stable condition to avoid changes in the loading conditions.
Previous study by found a more sensitivity of $94 \%$ (Tsai et al., 2011).

Global longitudinal strain has been introduced as an index of global LV function. 2D-STE has been validated as an accurate angle-independent measurement of regional and global myocardial deformation or strain (Hare et al., 2009 and Marwick et al., 2009).

The subendocardial layer is often first affected by diseases. Because the myocardial fibers in this layer are mainly responsible for long-axis contraction, a reduction in longitudinal function has been found to be an early and accurate indicator of LV dysfunction with high susceptibility to ischemia, fibrosis, and hypertrophy (Ganame et al., 2007).

This was reflected in our study, in which the longitudinal strain was significantly different in the two groups. These results were confirmed by Tsai et al. (2011) who demonstrated LV dysfunction in the anthracycline-treated patients compared to the healthy subjects, with a significantly lower global longitudinal strain despite a preserved LVEF $50 \%$ in the anthracycline group.

Myocardial deformation (strain) and the rate of deformation (strain rate) reflect intrinsic contractility of the myocardium. Sawaya et al. (2011) demonstrated that regional myocardial strain (longitudinal, radial, and circumferential) is significantly decreased in patients treated with anthracycline and trastuzumab before decrease of EF, and also that can predict further changes in $\mathrm{EF}$.

Similarly, Bi et al. (2009) demonstrated a significant early reduction of longitudinal strain after treatment with 
epirubicin. However, other study failed to reveal a decrease of myocardial strain after chemotherapy (Hale et al., 2009).

These suggest that deformation parameters are a sensitive tool to detect early changes of contractile function after epirubicin. STI also offers the unique opportunity to assess rotational deformation of the LV, with good agreement with tagged CMR (Halle-Valle et al., 2005).

Therefore, it has been demonstrated the usefulness of new echocardiographic techniques, such as TVI and STI, for early detection of impairment of contractile myocardial function, before alteration in global systolic LV function, suggesting that these can be used in clinical practice in order to identify patients at risk for development of irreversible cardiac failure and to implement special preventive and therapeutic measures in patients with breast cancer treated with chemotherapy. These parameters should be now incorporated into clinical protocols in order to optimize the monitoring of chemotherapy-induced cardiac toxicity (Florescu et al., 2013).

There are known published cases on cardiac conduction disturbances induced by 5 -FU or capecitabine. The cardiotoxic effects of these drugs seem to be multifactorial (Polk et al., 2014).

The suggested phenomenon of vasospasm induced by 5-FU or capecitabine cannot explain the possibility of cardiomyopathy, sinoatrial and atrioventricular node dysfunction, takotsubo cardiomyopathy, and QT prolongation with torsade de pointes ventricular tachycardia (Stewart et al., 2010).
In pediatric and adult patients receiving potentially cardiotoxic chemotherapy, the American Heart Association's class I recommendation has been to routinely perform echocardiography at baseline and at recurrence (Tsai et al., 2011).

Adult survivors have been recommended to undergo screening every 5 years, and patients with abnormal results should be monitored yearly. The evaluation of myocardial function with strain imaging can be an effective tool for long-term follow-up in patients receiving potentially cardiotoxic therapy (Ganame et al., 2007).

Abnormalities in 2D GLS and GCS have been demonstrated in multiple studies after cardiotoxic cancer therapy, including by our own group (Sawaya et al., 2012 and Narayan et al., 2016).

Two studies of 3D STE in adult's chemotherapy-treated different types of cancer reported reductions in 3D parameters with anthracyclines, but these studies were smaller, of shorter follow up duration, and did not investigate the association between changes in 3D parameters and subsequent systolic and diastolic function (Santoro et al., 2017 and Song et al., 2017).

While 3D STE has the potential to overcome some of the technical limitations of 2D STE by tracking the movement of speckles within the entire scan volume (Maffessanti et al., 2009 and Nesser et al., 2009), image quality and temporal resolution may limit 3D interpretability (Santoro et al., 2017 and Song et al., 2017).

Santoro and colleagues found that feasibility of 3D STE was only $60 \%$ while 
2D STE feasibility was $90 \%$. In Zhang et al. (2018) study, the reproducibility of 3D measures was greater than $2 \mathrm{D}$ and the analyzability of 3D STE in acquired images was $94 \%$, similar to the $90 \%$ feasibility in a healthy population study (Muraru et al., 2014).

Although a recent European Society of Cardiology statement on cardiovascular toxicity of cancer treatment emphasizes the ischemic effect of 5-FU (Zamorano et al., 2016), cardiotoxicity of pyrimidines seems to have numerous mechanisms, including apoptosis of myocardium, depletion of high-energy phosphate compounds, increased oxygen consumption, impaired antioxidant defense system, and more (Polk et al., 2014).

Despite the low to intermediate doxorubicin doses in Tsai et al. (2011) study, LV dysfunction was observed in patients 20 years after successful cancer treatment. Earlier studies have demonstrated that the risk of developing clinical heart failure 15 years after anthracycline therapy was estimated to be approximately $5 \%$ after treatment of childhood cancer (Ganame et al., 2007).

A decreased ventricular systolic reserve has been noted in asymptomatic children treated with low-dose anthracycline for 1 year (Guimaraes-Filho et al., 2007).

The clinical course of myocardial function in adult anthracycline-treated cancer survivors has not been fully explored owing to the short follow-up periods and variations in treatment algorithms. Tsai et al. (2011) reported significant LV remodeling in the cancer survivors 2 decades after radiotherapy with chemotherapy. The differences in LV function due to anthracycline therapy, however, could not be detected using traditional echocardiographic methods.

\section{CONCLUSION}

A substantial impairment of LV systolic function was detected in cancer colon patients receiving chemotherapy with apparently preserved LV systolic function as evidenced by reduction in global longitudinal strain using twodimensional speckle tracking echocardiography.

\section{REFERENCES}

1. Balloni L, Porta C, Rossi S, Gola A, Pugliese P, Ferrari S, Bovio A, Danova M and Riccardi A (2000): Left ventricular function in colon cancer patients receiving adjuvant fluoro-folate chemotherapy: an echocardiographic study. Oncol Rep., 7(4): 887-890.

2. Bi X, Deng Y, Zeng F, Zhu Y, Wu Y, Zhao $\mathrm{C}$ and Li C (2009): Evaluation of epirubicininduced cardiotoxicity by two-dimensional strain echocardiography in breast cancer patients. J Huazhong Univ Sci Technolog Med Sci, 29:39-44.

3. Brana I and Tabernero J (2010): Cardiotoxicity. Ann Oncol., 21:173-179.

4. Cardinale D, Colombo A, Lamantia G Colombo N, Civelli M, De Giacomi G, Rubino M, Veglia F, Fiorentini $C$ and Cipolla CM (2010): Anthracycline-induced cardiomyopathy: Clinical relevance and response to pharmacologic therapy. JACC, 55: 213-220.

5. Ferlay J, Soerjomataram I, Dikshit R, Eser S, Mathers C, Rebelo M, Parkin DM, Forman D and Bray F (2015): Cancer incidence and mortality worldwide: sources, methods and major patterns in GLOBOCAN 2012. Int J Cancer, 136: E359-E386.

6. Florescu $M$, Cinteza $M$ and Vinereanu $D$ (2013):

Chemotherapy-induced 
Cardiotoxicity. Maedica (Buchar), 8(1):5967.

7. Ganame J, Claus P, Uyttebroeck A, Renard M, D'Hooge J, Bijnens B, Sutherland GR, Eyskens B and Mertens L (2007): Myocardial dysfunction late after low-dose anthracycline treatment in asymptomatic pediatric patients. J Am Soc Echocardiogr, 20: 1351-1358.

8. Gjesdal O, Helle-Valle T, Hopp E, Lunde K, Vartdal T, Aakhus S, Smith HJ, Ihlen $H$ and Edvardsen $T$ (2008): Noninvasive separation of large, medium, and small myocardial infarcts in survivors of reperfused ST-elevation myocardial infarction: a comprehensive tissue Doppler and speckletracking echocardiography study. Circ Cardiovasc Imaging, 1:189-196.

9. Gjesdal O, Hopp E, Vartdal T, Lunde K, Helle-Valle T, Aakhus S, Smith HJ, Ihlen $H$ and Edvardsen $T$ (2007): Global longitudinal strain measured by twodimensional speckle tracking echocardiography is closely related to myocardial infarct size in chronic ischaemic heart disease. Clin Sci, 113:287-296.

10. Guimaraes-Filho F, Tan D, Braga J, Rodrigues A, Waib $\mathbf{P}$ and Matsubara $B$ (2007): Ventricular systolic reserve in asymptomatic children previously treated with low doses of anthracyclines. Am J Cardiol., 100: 1303-1306.

11. Hale JL, Brown JK, Leano R, Jenkins C, Woodward N and Marwick TH (2009): Use of myocardial deformation imaging to detect preclinical myocardial dysfunction before conventional measures in patients undergoing breast cancer treatment with trastuzumab. Am Heart J, 158:294-301.

12. Halle-Valle $T$, Crosby $J$, Edvardsen $T$, Lyseggen E, Amundsen BH, Smith HJ, Rosen BD, Lima JA, Torp H, Ihlen H and Smiseth OA (2005): New non-invasive method for assessment of left ventricular rotation: speckle tracking echocardiography. Circulation, 112: 3149-3156.

13. Hare JL, Brown JK, Leano R, Jenkins C, Woodward N and Marwick TH (2009): Use of myocardial deformation imaging to detect preclinical myocardial dysfunction before conventional measures in patients undergoing breast cancer treatment with trastuzumab. Am Heart J, 158:294-301.

14. Jung KW, Won YJ, Kong HJ, Oh CM, Lee DH and Lee JS (2014): Prediction of cancer incidence and mortality in Korea, 2014. Cancer Res Treat., 46:124-130.

15. Khakoo AY, Liu PP, Force T, LopezBerestein G, Jones LW, Schneider J and Hill J. (2011): Cardiotoxicity due to cancer therapy. Tex Heart Inst J, 38:253-256.

16. Kosmas C, Kallistratos MS, Kopterides P, Syrios J, Skopelitis H, Mylonakis N, Karabelis $A$ and Tsavaris $N$ (2008): Cardiotoxicity of fluoropyrimidines in different schedules of administration: a prospective study. J Cancer Res Clin Oncol., 134(1): 75-82.

17. Maffessanti F, Nesser H-J, Weinert L, Steringer-Mascherbauer $\mathbf{R}$, Niel $\mathbf{J}$, Gorissen W, Sugeng L, Lang RM and Mor-Avi V (2009): Quantitative evaluation of regional left ventricular function using three-dimensional speckle tracking echocardiography in patients with and without heart disease. Am J Cardiol, 104(12):1755-62.

18. Marwick TH, Leano RL, Brown J, Sun JP, Hoffmann R, Lysyansky P, Becker M and Thomas JD (2009): Myocardial strain measurement with 2-dimensional speckletracking echocardiography: definition of normal range. J Am Coll Cardiol Imaging, $2: 80-84$.

19. Mercuro G, Cadeddou C, Piras A, Dessì M, Madeddu C, Deidda M, Serpe R, Massa E and Mantovani G (2007): Early epirubicin-induced myocardial dysfunction revealed by serial tissue Doppler echocardiography: correlation with inflammatory and oxidative stress markers. The Oncologist., 12:1124-1233.

20. Mornos C and Petrescu L (2013): Early detection of anthracycline-mediated cardiotoxicity: the value of considering both global longitudinal left ventricular strain and twist. Can J Physiol Pharmacol, 91: 601-7. 
21. Muraru D, Cucchini U, Mihăilă S, Miglioranza MH, Aruta P, Cavalli G, Cecchetto A, Padayattil-Josè S, Peluso D, Iliceto $S$ and Badano LP (2014): Left ventricular myocardial strain by threedimensional speckle tracking echocardiography in healthy subjects: Reference values and analysis of their physiologic and technical determinants. J Am Soc Echocardiogr., 27(8): 858-871.

22. Narayan HK., French B, Khan AM, Plappert T, Hyman D, Bajulaiye A, Domchek S, DeMichele A, Clark A, Matro J, Bradbury A, Fox K, Carver JR and Ky $B$ (2016): Noninvasive measures of ventricular-arterial coupling and circumferential strain predict cancer therapeutics-related cardiac dysfunction. JACC Cardiovasc Imaging, 9(10):1131-41.

23. Nesser H-J, Mor-Avi V, Gorissen W, Weinert L, Steringer-Mascherbauer $\mathbf{R}$, Niel J, Sugeng L and Lang RM (2009): Quantification of left ventricular volumes using threedimensional echocardiographic speckle tracking: comparison with MRI. Eur Heart J, 30(13): 1565-73.

24. Plana JC, Galderisi M, Barac A, Ewer MS, Ky B, Scherrer-Crosbie M, Ganame J, Sebag IA, Agler DA, Badano LP, Banchs J, Cardinale D, Carver J, Cerqueira $M$, DeCara JM, Edvardsen T, Flamm SD, Force T, Griffin BP, Jerusalem G, Liu JE, Magalhães A, Marwick T, Sanchez LY, Sicari R, Villarraga HR and Lancellotti $P$ (2014): Expert consensus for multimodality imaging evaluation of adult patients during and after cancer therapy. A report from the American Society of Echocardiography and the European Association of Cardiovascular Imaging. European Heart JournalCardiovascular Imaging, 15:1063-93.

25. Polk A, Vistisen $K$, Vaage-Nilsen $M$ and Nielsen DL (2014): A systematic review of the pathophysiology of 5-fluorouracilinduced cardiotoxicity. BMC Pharmacol Toxicol., 15: 47.

26. Reisner SA, Lysyansky P, Agmon Y, Mutlak D, Lessick $J$ and Friedman $Z$ (2004): Global longitudinal strain: a novel index of left ventricular systolic function. J Am Soc Echocardiogr, 17:630-633.

27. Santoro C, Arpino G, Esposito R, Lembo M, Paciolla I, Cardalesi C, de Simone G, Trimarco B, De Placido $S$ and Galderisi $M$ (2017): 2D and 3D strain for detection of subclinical anthracycline cardiotoxicity in breast cancer patients: a balance with feasibility. Eur Heart J Cardiovasc Imaging, 11: 930-6.

28. Sawaya H, Sebag IA, Plana JC, Januzzi JL, Ky B, Cohen V, Gosavi S, Carver JR, Wiegers SE, Martin RP, Picard MH, Gerszten RE, Halpern EF, Passeri J, Kuter I and Scherrer-Crosbie M (2011): Early detection and prediction of cardiotoxicity in chemotherapy-treated patients. Am J Cardiol., 107: 1375-1380.

29. Song FY, Shi J, Guo Y, Zhang CJ, Xu Y1, Zhang QL, Shu XH and Cheng LL (2017): Assessment of biventricular systolic strain derived from the two-dimensional and threedimensional speckle tracking echocardiography in lymphoma patients after anthracycline therapy. Int $\mathbf{J}$ Cardiovasc Imaging, 33(6):857-68.

30. Stewart T, Pavlakis N and Ward M (2010): Cardiotoxicity with 5-fluorouracil and capecitabine: more than just vasospastic angina. Intern Med J., 40(4): 303-307.

31. Telli ML, Hunt SA, Carlson RW and Guardino AE (2007): Trastuzumab-related cardiotoxicity: calling into question the concept of reversibility. J Clin Oncol, 25: 3525-33.

32. Thavendiranathan P, Poulin F, Lim KD, Plana JC, Woo A and Marwick TH (2014): Use of myocardial strain imaging by echocardiography for the early detection of cardiotoxicity in patients during and after cancer chemotherapy - A systematic review. J Am Coll Cardiol, 63:2751-68.

33. Tsai HR, Gjesdal O, Wethal T, Haugaa KH, Fosså A, Fosså SD and Edvardsen T (2011): Left ventricular function assessed by two-dimensional speckle tracking echocardiography in long-term survivors of Hodgkin's lymphoma treated by mediastinal 
radiotherapy with or without anthracycline therapy. Am J Card., 107(3): 472 - 477.

34. Venneri L, Zoppellaro $G$ and Khattar RS (2018): Cardio-oncology: the role of advanced echocardiography in cancer patients. Expert Rev Cardiovasc Ther., 16(4):249-258.

35. Yancy CW, Jessup M, Bozkurt B, Butler J, Casey DE Jr, Drazner MH, Fonarow GC, Geraci SA, Horwich T, Januzzi JL, Johnson MR, Kasper EK, Levy WC, Masoudi FA, McBride PE, McMurray JJ, Mitchell JE, Peterson PN, Riegel B, Sam F, Stevenson LW, Tang WH, Tsai EJ, Wilkoff BL; American College of Cardiology Foundation; American Heart Association Task Force on Practice Guidelines (2013): 2013 ACCF/AHA guideline for the management of heart failure: a report of the American College of Cardiology Foundation/American Heart Association Task Force on Practice Guidelines. J Am Coll Cardiol, 62:1495539.

36. Yingchoncharoen T, Agarwal S, Popović ZB and Marwick TH (2013): Normal ranges of left ventricular strain: a metaanalysis. J Am Soc Echocardiogr, 26:185-91.
37. Zamorano JL, Lancellotti P, Rodriguez Muñoz D, Aboyans V, Asteggiano R, Galderisi M, Habib G, Lenihan DJ, Lip GYH, Lyon AR, Lopez Fernandez T, Mohty D, Piepoli MF, Tamargo J, Torbicki A, Suter TM; and ESC Scientific Document Group (2016): Authors/Task Force Members, ESC Committee for Practice Guidelines (CPG): 2016 ESC Position Paper on cancer treatments and cardiovascular toxicity developed under the auspices of the ESC Committee for Practice Guidelines: The Task Force for cancer treatments and cardiovascular toxicity of the European Society of Cardiology (ESC). Eur Heart J, 37(36): 2768-2801.

38. Zhang KW, Finkelman BS, Gulati G, Narayan HK, Upshaw J, Narayan V, Plappert T, Englefield V, Smith AM, Zhang C, Hundley WG and Ky B (2018): Abnormalities in 3-dimensional left ventricular mechanics with anthracycline chemotherapy are associated with systolic and diastolic dysfunction. JACC Cardiovasc Imaging, 11(8):1059-1068. 


\section{الكشف قبل السريري من العلاج الكيميائي الناجم عن إختلال وظيفة

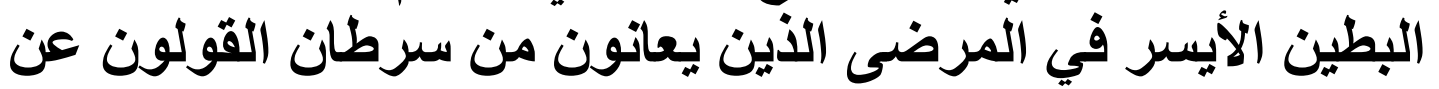 طريق الموجات الصوتية علي القلب من فئبن}

محد عبدالففار سالم، وائل محمد عطية، أيمن صادق السعيد

قسم أمراض القلب، كلية الطب، جامعة الأزهر، القاهره

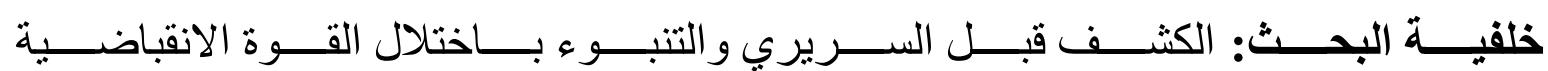

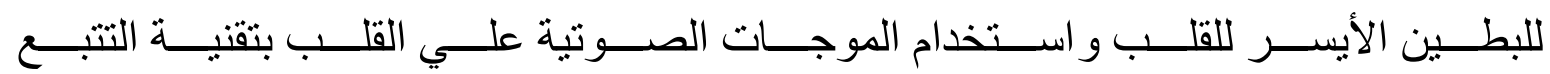

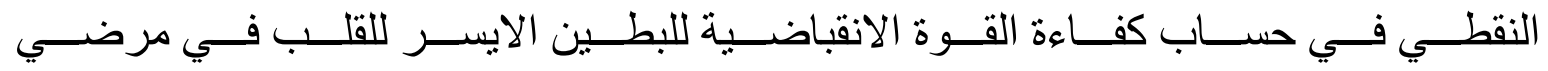

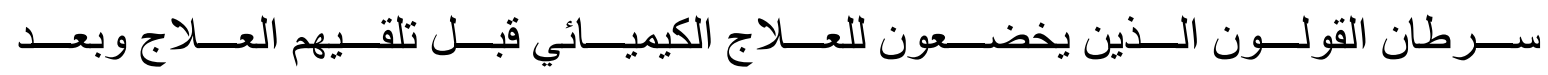
تلقيهم للعلاج الكيميائي.

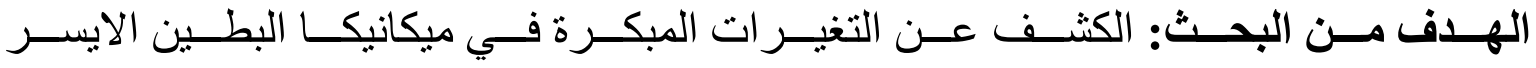

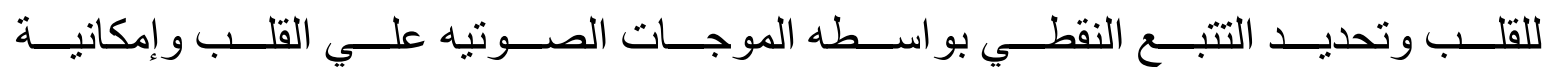

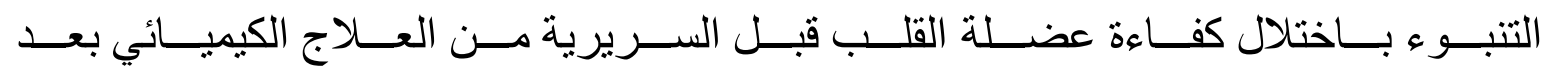

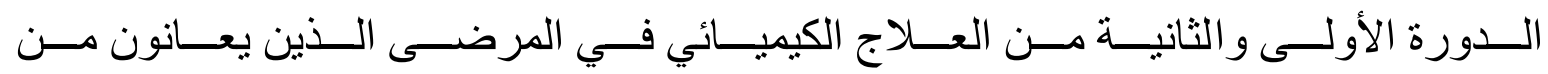
سرطان القولون.

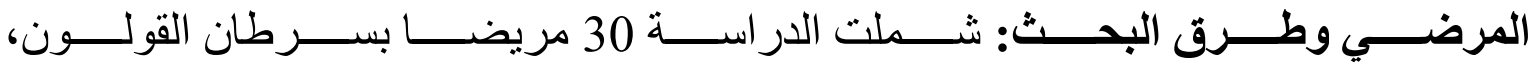

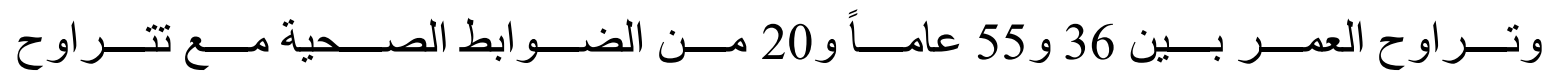

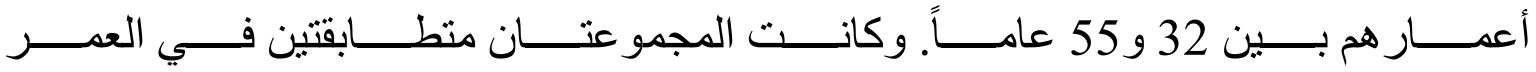

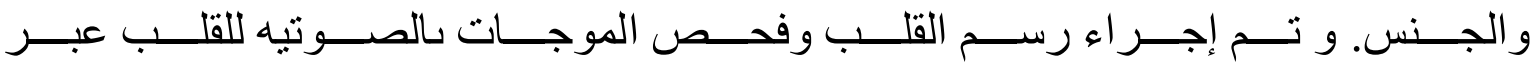
الصدر وصدى التتبع لجميع الأشخاص.

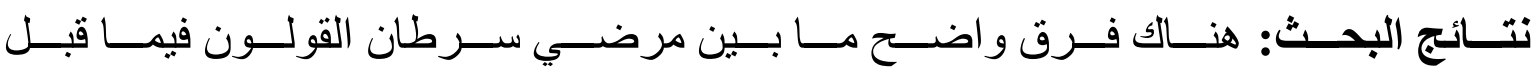

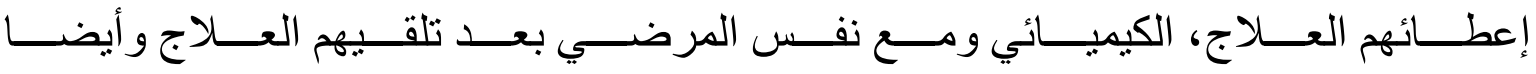

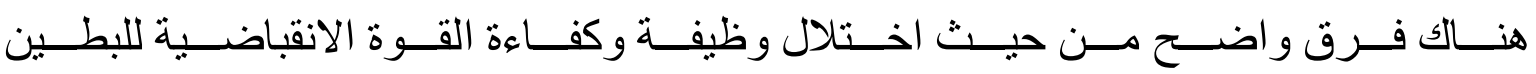

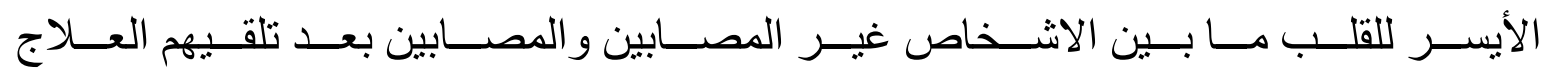

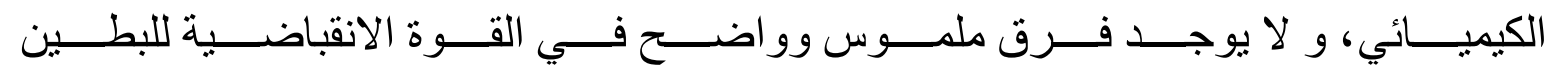




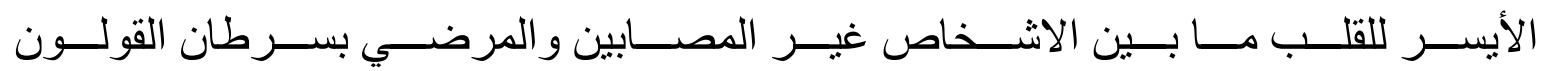
قبل إعطائهم العلاج الكيميائي.

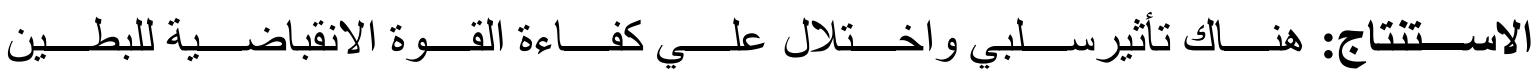

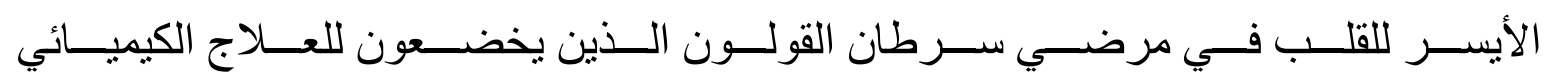

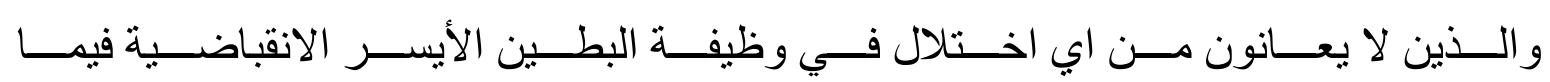

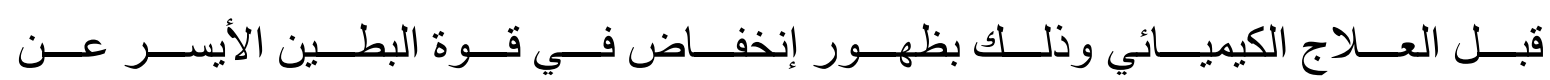

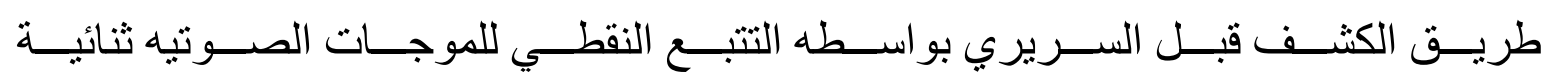
الابعاد علي القلب. 